\title{
Effect of blood type on survival of Chinese patients with esophageal squamous cell carcinoma
}

\author{
This article was published in the following Dove Press journal: \\ OncoTargets and Therapy \\ 23 April 2015 \\ Number of times this article has been viewed
}

\author{
Jian Qin ${ }^{1, *}$ \\ San-Gang $\mathrm{Wu}^{2}, *$ \\ Jia-Yuan Sun ${ }^{3}$ \\ Huan-Xin $\operatorname{Lin}^{3}$ \\ Zhen-Yu $\mathrm{He}^{3}$ \\ Qun $\mathrm{Li}^{3}$
}

'Department of Radiation Oncology of Clinical Cancer Center, the

People's Hospital of Guangxi

Zhuang Autonomous Region,

Nanning, People's Republic of China;

2Department of Radiation Oncology,

Xiamen Cancer Center, the First

Affiliated Hospital of Xiamen

University, Xiamen, People's Republic

of China; ${ }^{3}$ Sun Yat-sen University

Cancer Center, State Key Laboratory

of Oncology in South China,

Department of Radiation Oncology,

Collaborative Innovation Center

of Cancer Medicine, Guangzhou,

People's Republic of China

*These authors contributed equally to this work
Correspondences: Zhen-Yu He; Qun Li Sun Yat-sen University Cancer Center, 65I Dongfeng East Road, Guangzhou 510060, People's Republic of China; State Key Laboratory of Oncology in South China, Department of Radiation Oncology, Collaborative Innovation

Center of Cancer Medicine, Guangzhou, People's Republic of China

Tel +862087343543

Fax +86 2087343392

Email hezhy@sysucc.org.cn;

liqun0799@।26.com
Background: The aim of this study was to evaluate the prognostic value of $\mathrm{ABO}$ blood group in Chinese patients with esophageal squamous cell carcinoma (ESCC) after esophagectomy. Methods: This study was a retrospective review of the records of 548 patients with ESCC who received cytoreductive surgery between October 2002 and March 2007. The prognostic impact of ABO blood group on overall survival (OS) was analyzed.

Results: The median follow-up time was 37 months, and the 5-year OS was $43.3 \%$. The overall 5 -year OS was $41.2 \%, 49.7 \%, 44.0 \%$, and $29.8 \%$ for the A, B, O, and $\mathrm{AB}$ groups, respectively $(P=0.038)$. Among patients with negative lymph nodes (LNs), the 5-year OS was $59.0 \%, 68.2 \%$, $57.9 \%$, and $28.6 \%$ for the $\mathrm{A}, \mathrm{B}, \mathrm{O}$, and $\mathrm{AB}$ groups, respectively $(P<0.001)$, but blood type had no value in predicting the OS of patients with positive LNs $(P=0.524)$. In multivariate Cox regression analysis of all patients, $\mathrm{ABO}$ blood group was not an independent prognostic factor of OS. However, in patients with negative LNs, blood type was an independent prognostic factor of $\mathrm{OS}$, and the higher risk of death for patients of type $\mathrm{AB}$ versus non- $\mathrm{AB}$ significant in multivariate analyses (hazard ratio [HR], 2.576; 95\% confidence interval [CI], 1.349-4.919; $P=0.004$ ).

Conclusion: ABO blood group is associated with survival in Chinese patients with ESCC. Patients with blood type AB had a significantly worse OS than patients with non-AB type, especially in patients with negative LNs.

Keywords: esophageal squamous cell carcinoma, ABO blood-group system, prognosis, lymph node, survival

\section{Introduction}

Esophageal cancer (EC) is a highly fatal gastrointestinal malignancy. ${ }^{1}$ In People's Republic of China, EC, which is predominantly squamous cell carcinoma (ESCC; $90 \%$ of cases), is the fifth most common cancer and the fourth leading cause of cancer-related deaths. ${ }^{2}$ Lymph node (LN) metastasis, grade of differentiation, location of the primary tumor, and depth of primary tumor infiltration are the most common prognostic factors in ESCC, all of which are factors of the 7th edition of the Union for International Cancer Control and the American Joint Committee on Cancer (UICC/ AJCC) Tumor, Node, Metastasis (TNM) staging system. ${ }^{3}$ Although prognostic factors for ESCC have been intensively studied, including in the field of molecular biology, prognoses differ despite similar stages. Identification of biomarkers that are readily available, inexpensive, and reproducible could improve the prognosis of patients and help physicians in providing individualized therapies.

Recently, the association between ABO blood group and survival has been evaluated in several malignancies, including pancreatic cancer, ${ }^{4}$ colon cancer, ${ }^{5}$ nasopharyngeal carcinoma, ${ }^{6}$ and breast cancer. ${ }^{7}$ Previous studies have suggested that blood type B was associated with an increased risk of EC.$^{8-10}$ However, to date, controversy remains 
over the clinical value of $\mathrm{ABO}$ blood group to predict the prognosis of ESCC. ${ }^{11-13}$ Therefore, the aim of this retrospective analysis was to assess the relationship between blood type and survival among Chinese patients with ESCC who underwent esophagectomy as their primary treatment.

\section{Materials and methods \\ Patients}

This study enrolled 548 patients with ESCC who received radical esophagectomy between October 2002 and March 2007. The inclusion criteria were as follows: 1) resectable ESCC with radical esophagectomy and $\mathrm{LN}$ dissection; 2) staging of ESCC as primary (p)T1-3N0-3M0 according to the 7 th edition of the UICC/AJCC TNM staging system; 3) negative surgical margin (R0); 4) no preoperative radiotherapy or chemotherapy; and 5) ESCC located in the thoracic esophagus. The study was performed in accordance with the Declaration of Helsinki and was approved by the ethics committee of Sun Yat-Sen University Cancer Center. All patients provided written informed consent for storage of their medical records in the hospital database and for use of this information in our research.

\section{Clinicopathological factors}

Clinicopathological factors were used to assess the risk of death. Factors examined included age, sex, tumor location, pT stage, pN stage, histologic grade, smoking, alcohol consumption, and ABO blood group. An ever smoker was defined as one who smoked at least once a day for more than 1 year, and a drinker was defined as one who drank alcohol more than $100 \mathrm{~mL} /$ day for more than 1 year.

\section{Follow-up and survival endpoints}

Follow-up was performed every 3-6 months after surgery via a hospital visit, telephone call, or letter. The endpoint of the study was overall survival (OS). OS was calculated as the period from the date of diagnosis to the date of death from any cause or to the date of the last follow-up.

\section{Statistical analysis}

The $\chi^{2}$ and Fisher's exact tests were used to analyze the differences between qualitative data. Survival rates were plotted by the Kaplan-Meier method and compared by using the log-rank test. A stepwise Cox regression model was used for multivariate analysis. Factors that were significant indicators of endpoints in the univariate analysis were included in the stepwise Cox regression analysis. All data were analyzed with the SPSS statistical software package, version 16.0
(IBM Corporation, Armonk, NY, USA). A $P$-value $<0.05$ was considered statistically significant.

\section{Results}

\section{Patient characteristics}

A total of 548 eligible patients with ESCC were identified at our institution during the study period of October 2002 to March 2007. The median age of the patients was 57 years (range: 30-82 years). The distribution of blood type was as follows: 164 patients $(29.9 \%)$ with blood type A; 134 (24.5\%) with blood type B; 202 (36.8\%) with blood type O; and $48(8.8 \%)$ with blood type AB. Of these, 349 (63.7\%) patients were smokers, and $115(21.0 \%)$ were drinkers. Table 1 summarizes the characteristics of the study population. Analysis with the $\chi^{2}$ test showed that blood type was positively correlated with tumor location $(P=0.004), \mathrm{pN}$ stage $(P=0.001)$, smoking $(P=0.035)$, and histologic grade $(P=0.028)$.

By analyzing the postoperative complications, 103 patients had postoperative complications, including 38 patients with pulmonary complications, 23 patients with anastomosis leakage, 17 patients with cardiac complications, 15 with wound infection, and 10 patients with other complications.

\section{Effect of $A B O$ blood group on survival}

The median follow-up time was 37 months (range: 6-131 months). Of the 548 enrolled patients, 331 had died, of whom 323 died of ESCC-related diseases, 3 of cardiovascular diseases, and 5 of other diseases. The 5-year OS for all patients was $43.3 \%$. In the Kaplan-Meier analysis, blood type was associated with OS, the 5-year OS was $41.2 \%$, $49.7 \%, 44.0 \%$, and $29.8 \%$ for patients with the A, B, O, and $\mathrm{AB}$ blood type, respectively ( $P=0.038$; Table 2$)$. For patients with negative LNs, univariate analysis showed that ABO blood group affected the prognosis of survival, with a 5 -year OS of $59.0 \%, 68.2 \%, 57.9 \%$, and $28.6 \%$ for patients with the A, B, O, and AB blood type, respectively $(P<0.001$; Figure 1). In contrast, blood type had no value in predicting the prognosis of patients with positive LNs $(P=0.524$; Table 2). Furthermore, when the prognostic impact of $A B$ and non-AB types was compared, patients with type $A B$ had a significantly poorer 5-year OS than did patients with a non-AB blood type $(29.8 \%$ vs $44.6 \%, P=0.024)$. Finally, among patients with LN-negative ESCC, the 5-year OS of those with $\mathrm{AB}$ and non-AB blood types was $14.3 \%$ and $61.2 \%$, respectively $(P<0.001$; Figure 2$)$.

To determine whether ABO blood group could serve as an independent prognostic factor, we used Cox proportional 
Table I Correlation between ABO blood group and clinicopathological factors

\begin{tabular}{|c|c|c|c|c|c|c|}
\hline \multirow[t]{2}{*}{ Characteristic } & \multirow{2}{*}{$\frac{\text { All patients }}{n}$} & \multicolumn{4}{|c|}{ Patient blood type } & \multirow[t]{2}{*}{$P$} \\
\hline & & $\begin{array}{l}A(\%) \\
(n=164)\end{array}$ & $\begin{array}{l}\text { B (\%) } \\
(n=134)\end{array}$ & $\begin{array}{l}O(\%) \\
(n=202)\end{array}$ & $\begin{array}{l}A B(\%) \\
(n=48)\end{array}$ & \\
\hline \multicolumn{7}{|l|}{ Age (years) } \\
\hline$\leq 60$ & 341 & $105(64.0)$ & $87(64.9)$ & II 5 (56.9) & $34(70.2)$ & 0.207 \\
\hline$>60$ & 207 & $59(36.0)$ & $47(35.1)$ & $87(43.1)$ & $14(29.2)$ & \\
\hline \multicolumn{7}{|l|}{ Sex } \\
\hline Male & 407 & II $5(70.1)$ & $103(76.9)$ & I5I (74.8) & $38(79.2)$ & 0.462 \\
\hline Female & $|4|$ & 49 (29.9) & $31(23.1)$ & $5 \mathrm{I}(25.2)$ & $10(20.8)$ & \\
\hline \multicolumn{7}{|l|}{ Tumor location } \\
\hline Upper third & 34 & $13(7.9)$ & $2(1.5)$ & $13(6.4)$ & $6(12.5)$ & 0.004 \\
\hline Middle third & 234 & $82(50.0)$ & $54(40.3)$ & $84(4 I .6)$ & $14(29.2)$ & \\
\hline Lower third & 280 & $69(42.1)$ & $78(58.2)$ & $105(52.0)$ & $28(58.3)$ & \\
\hline \multicolumn{7}{|l|}{ Tumor stage } \\
\hline PTI & 14 & $2(1.2)$ & $4(3.0)$ & $6(3.0)$ & $2(4.2)$ & 0.649 \\
\hline $\mathrm{pT} 2$ & $|5|$ & $50(30.5)$ & $34(25.4)$ & $57(28.2)$ & $10(20.8)$ & \\
\hline pT3 & 383 & $112(68.3)$ & $96(71.6)$ & $139(68.8)$ & $36(75.0)$ & \\
\hline \multicolumn{7}{|l|}{ Node stage } \\
\hline pNo & 298 & $82(50.0)$ & $83(61.9)$ & 119 (58.9) & $14(29.2)$ & 0.001 \\
\hline $\mathrm{pNI}$ & 138 & $56(34.1)$ & $25(18.7)$ & $4 \mid(20.3)$ & $16(33.3)$ & \\
\hline $\mathrm{pN} 2$ & 88 & $22(13.4)$ & $21(15.7)$ & $31(15.3)$ & 14 (29.2) & \\
\hline pN3 & 24 & $4(2.5)$ & $5(3.7)$ & II (5.5) & $4(8.3)$ & \\
\hline \multicolumn{7}{|l|}{ Histological grade } \\
\hline GI & 101 & $32(19.5)$ & $28(20.9)$ & $35(17.3)$ & $6(12.5)$ & 0.028 \\
\hline $\mathrm{G} 2$ & 275 & $79(48.2)$ & $77(57.5)$ & IOI (50.0) & $18(37.5)$ & \\
\hline G3 & 172 & $53(32.3)$ & $29(21.6)$ & $66(32.7)$ & $24(50.0)$ & \\
\hline \multicolumn{7}{|l|}{ Smoking } \\
\hline Never & 199 & $60(36.6)$ & $44(32.8)$ & $85(42.1)$ & $10(20.8)$ & 0.035 \\
\hline Ever & 349 & $104(63.4)$ & $90(67.2)$ & 117 (57.9) & $38(79.2)$ & \\
\hline \multicolumn{7}{|c|}{ Alcohol consumption } \\
\hline No & 433 & $130(79.3)$ & $108(80.6)$ & $160(79.2)$ & 35 (72.9) & 0.732 \\
\hline Yes & 115 & $34(20.7)$ & $26(19.4)$ & $42(20.8)$ & $13(27.1)$ & \\
\hline
\end{tabular}

Abbreviations: $G$, grade; $N$, node; $p$, primary; $T$, tumor.

hazards models to examine OS. For all patients, blood type was not associated with survival in a univariate Cox regression analysis (hazard ratio [HR], 0.906; 95\% confidence interval [CI], 0.812-1.011; $P=0.078)$. However, in a subgroup analysis of patients whose LNs were negative, the $\mathrm{HR}$ for OS among patients with blood type A, B, and O relative to those with type $\mathrm{AB}$ was $0.318(95 \% \mathrm{CI}, 0.166-$ 0.609; $P=0.001), 0.226$ (95\% CI, 0.115-0.443; $P<0.001$ ), and 0.319 (95\% CI, 0.17-0.597; $P<0.001)$, respectively. No significant differences in OS were observed among patients with blood type $\mathrm{A}, \mathrm{B}$, and $\mathrm{O}$. As with multivariate Cox regression analysis, $\mathrm{ABO}$ blood group was an independent prognostic factor of OS only for patients with negative LNs, with a higher risk of death for patients with type $\mathrm{AB}$ versus a non-AB type (HR, 2.576; 95\% CI, 1.349-4.919; $P=0.004$; Table 3). Other significant prognostic factors among all patients included sex, pN stage, histologic grade, and alcohol consumption.

\section{Discussion}

In the present study, we investigated the value of $\mathrm{ABO}$ blood group in predicting the prognosis of patients who underwent radical surgery for ESCC. The results showed that blood type is an independent factor affecting the prognosis of patients with ESCC, especially for those without LN metastasis.

Many studies have examined the value of ABO blood group in predicting the risk of various solid tumors and hematologic malignancies. ${ }^{14-17}$ It was found that the risk of EC increased significantly in patients with blood type B. ${ }^{8-10}$ However, controversy still exists regarding the ability of ABO blood group to predict prognosis. Sun et al studied patients with ESCC who had a history of smoking and found that the $\mathrm{B}$ and $\mathrm{O}$ blood types were negatively associated with survival, ${ }^{11}$ and Yang et al suggested that the survival of patients with blood type $\mathrm{O}$ was significantly poorer than that of patients with other blood types..$^{12}$ However, Nozoe et al found no correlation between $\mathrm{ABO}$ blood group 
Table 2 Univariate analysis of the association between prognosis and lymph node status in patients with esophageal cancer

\begin{tabular}{|c|c|c|c|c|c|c|c|c|c|}
\hline \multirow[t]{2}{*}{ Characteristic } & \multicolumn{3}{|l|}{ All patients } & \multicolumn{3}{|c|}{ Lymph node-negative } & \multicolumn{3}{|c|}{ Lymph node-positive } \\
\hline & $\begin{array}{l}\text { 5-year } \\
\text { survival (\%) }\end{array}$ & $\begin{array}{l}\text { Median survival } \\
\text { (months) }\end{array}$ & $P$ & $\begin{array}{l}\text { 5-year } \\
\text { survival (\%) }\end{array}$ & $\begin{array}{l}\text { Median survival } \\
\text { (months) }\end{array}$ & $P$ & $\begin{array}{l}5 \text {-year } \\
\text { survival (\%) }\end{array}$ & $\begin{array}{l}\text { Median survival } \\
\text { (months) }\end{array}$ & $P$ \\
\hline \multicolumn{10}{|l|}{ Age (years) } \\
\hline$\leq 60$ & 44.1 & 40.8 & 0.326 & 60.2 & - & 0.315 & 25.8 & 21.1 & 0.105 \\
\hline$>60$ & 40.4 & 40.9 & & 54.8 & 73.8 & & 17.1 & 18.4 & \\
\hline \multicolumn{10}{|l|}{ Sex } \\
\hline Male & 39.9 & 36.0 & 0.006 & 57.5 & 109.8 & 0.398 & 21.0 & 21.6 & 0.019 \\
\hline Female & 53.4 & 74.8 & & 62.4 & - & & 37.3 & 39.8 & \\
\hline \multicolumn{10}{|l|}{ Tumor location } \\
\hline Upper third & 36.6 & 35.2 & 0.758 & 45.9 & 58.7 & 0.188 & 23.3 & 21.0 & 0.905 \\
\hline Middle third & 44.7 & 42.9 & & 56.9 & 89.0 & & 26.4 & 26.8 & \\
\hline Lower third & 43.0 & 40.4 & & 62.9 & & & 23.2 & 23.0 & \\
\hline \multicolumn{10}{|l|}{ Tumor stage } \\
\hline PTI-T2 & 54.1 & 74.8 & 0.001 & 66.0 & - & 0.111 & 28.3 & 33.2 & 0.262 \\
\hline pT2 & 38.7 & 33.5 & & 54.8 & 89.9 & & 23.3 & 22.1 & \\
\hline \multicolumn{10}{|l|}{ Node stage } \\
\hline pNO & 59.0 & - & $<0.001$ & & - & - & & - & \\
\hline $\mathrm{pNI}$ & 31.3 & 34.6 & & & - & & 31.1 & 34.6 & $<0.001$ \\
\hline $\mathrm{pN} 2$ & 16.9 & 18.9 & & & - & & 16.9 & 18.9 & \\
\hline pN3 & 9.2 & 7.2 & & & - & & 9.2 & 7.2 & \\
\hline \multicolumn{10}{|c|}{ Histological grade } \\
\hline $\mathrm{GI}$ & 52.3 & - & 0.001 & 68.1 & - & 0.011 & 24.1 & 18.6 & 0.923 \\
\hline G2 & 45.1 & 46.6 & & 60.6 & - & & 22.7 & 27.2 & \\
\hline G3 & 35.1 & 26.8 & & 46.8 & 44.2 & & 26.4 & 21.6 & \\
\hline \multicolumn{10}{|l|}{ ABO blood group } \\
\hline A & 41.2 & 36.0 & 0.038 & 59.0 & 89.9 & $<0.001$ & 23.3 & 21.6 & 0.524 \\
\hline B & 49.7 & 51.8 & & 68.2 & - & & 18.9 & 24.9 & \\
\hline 0 & 44.0 & 42.9 & & 57.9 & 112.6 & & 23.3 & 23.0 & \\
\hline$A B$ & 29.8 & 26.8 & & 28.6 & 22.4 & & 36.5 & 26.8 & \\
\hline \multicolumn{10}{|l|}{ Smoking } \\
\hline Never & 49.0 & 55.1 & 0.028 & 60.7 & - & 0.703 & 29.7 & 32.9 & 0.063 \\
\hline Ever & 40.1 & 36.3 & & 57.8 & - & & 22.1 & 21.1 & \\
\hline \multicolumn{10}{|c|}{ Alcohol consumption } \\
\hline No & 47.3 & 47.3 & $<0.001$ & 63.5 & - & $<0.001$ & 27.8 & 26.8 & 0.001 \\
\hline Yes & 28.7 & 29.7 & & 42.5 & 41.6 & & 11.8 & 15.9 & \\
\hline
\end{tabular}

Abbreviations: $G$, grade; $N$, node; $p$, primary; $T$, tumor.

and prognosis. ${ }^{13}$ Among the 548 patients in the present study, the proportions of blood types $\mathrm{A}, \mathrm{B}, \mathrm{O}$, and $\mathrm{AB}$ were similar to those of the above-mentioned studies. ${ }^{15-17}$ As a result, our study clarifies the prognostic value of $\mathrm{ABO}$ blood groups for survival among Chinese patients with ESCC. However, the results of the present study showed that the prognosis of patients with blood type $A B$ was significantly poorer than that of patients with other blood types, especially in patients whose LNs were negative. A multivariate analysis determined that blood type $\mathrm{AB}$ is an independent factor affecting the survival of patients with ESCC. Though the distribution of blood groups with ESCC in the present study was similar to those of other studies, the reasons for the observed differences in results are unknown. The conflicting results could be due to the heterogeneity of study populations, differences in patient characteristics, or limited study sizes.
The prognosis of patients with ESCC and without LN metastases is known to be better than that of patients whose LNs are positive. Factors that negatively affect the prognosis of patients with LN-negative ESCC include age, depth of invasion, the length of the primary tumor, histologic grade, and behaviors such as smoking and drinking. ${ }^{18-20}$ The multivariate analysis in the present study showed that alcohol consumption, histologic grade, and $\mathrm{AB}$ blood type had a negative impact on the prognoses of patients with negative LNs. The disparate results in patients with and without LN metastases might be due to the following potential reason: ESCC patients with positive LNs have a higher cancer load and the status of positive LNs themselves is a high risk factor for a poor prognosis. Among our patients with blood type $A B$ had tumors that were primarily $G 3$, which might imply that these patients' tumors had specific biological 


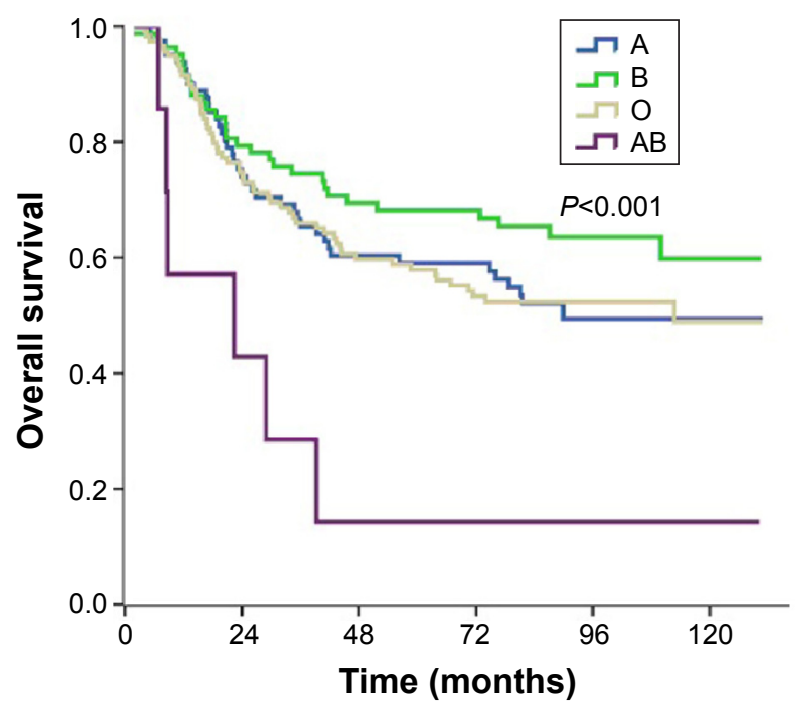

Figure I Overall survival of patients with lymph node-negative esophageal squamous cell carcinoma stratified by $\mathrm{ABO}$ blood group.

Notes: Kaplan-Meier analysis of overall survival ( $y$-axis) overtime ( $x$-axis) in patients with lymph node-negative esophageal squamous cell carcinoma. Survival was shortest among patients with type $A B$ blood $(P<0.001)$.

behaviors. Based on these data, we hypothesize that the genetic background associated with type $\mathrm{AB}$ blood might predispose ESCC to a poorer prognosis.

It remains uncertain why the $\mathrm{ABO}$ blood group antigens affect the survival of patients with EC. However, a growing number of studies have examined this issue, and the

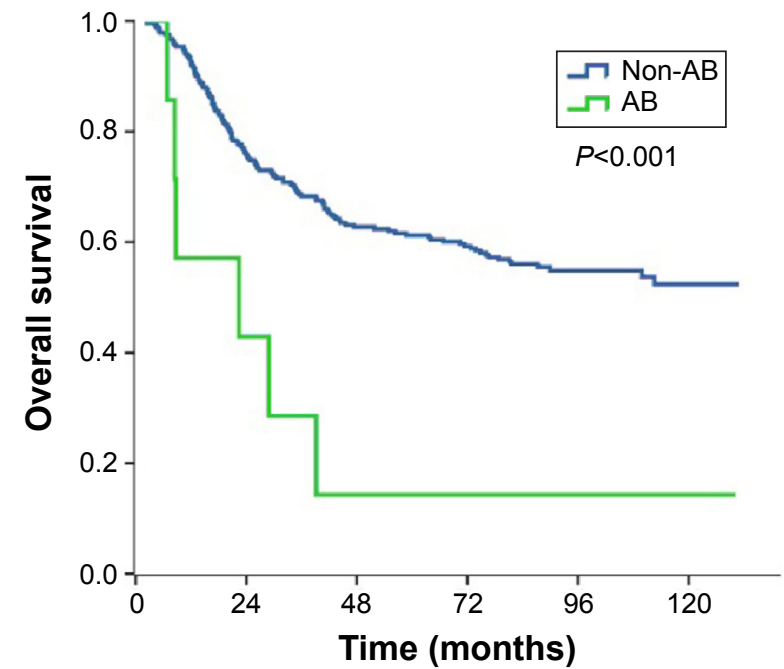

Figure 2 Overall survival of patients with lymph node-negative esophageal squamous cell carcinoma stratified by $A B$ blood type.

Notes: Kaplan-Meier analysis of overall survival ( $y$-axis) overtime ( $x$-axis) in patients with lymph node-negative esophageal squamous cell carcinoma. Survival was longer among patients with $\mathrm{A}, \mathrm{B}$, or $\mathrm{O}$ blood types than among those with type $A B(P<0.001)$.

possible mechanisms include inflammation, immunosurveillance of cancer cells, intracellular adhesion, and membrane signaling. ${ }^{21}$ In addition, the expression of blood group antigens on cancer cells is modified by hypermethylation of the $A B O$ promoter, and this hypermethylation might be related to tumor invasion and metastasis. ${ }^{22}$

Table 3 Multivariate analysis of the association between prognosis and lymph node status in patients with esophageal cancer

\begin{tabular}{|c|c|c|c|c|c|c|}
\hline \multirow[t]{2}{*}{ Characteristic } & \multicolumn{3}{|c|}{ All patients } & \multicolumn{3}{|c|}{ Lymph node-negative } \\
\hline & HR & $95 \% \mathrm{Cl}$ & $P$ & HR & $95 \% \mathrm{Cl}$ & $P$ \\
\hline \multicolumn{7}{|l|}{ Sex } \\
\hline Male & I & & & - & & \\
\hline Female & 0.634 & $0.483-0.832$ & 0.001 & - & - & - \\
\hline \multicolumn{7}{|l|}{ Tumor stage } \\
\hline PTI-2 & I & & & - & & \\
\hline pT3 & 1.227 & $0.95 \mathrm{I}-1.583$ & 0.116 & - & - & - \\
\hline \multicolumn{7}{|l|}{ Node stage } \\
\hline pNO & I & & & - & & \\
\hline $\mathrm{pNI}$ & 2.025 & $1.558-2.632$ & $<0.001$ & - & - & - \\
\hline $\mathrm{pN} 2$ & 3.262 & $2.449-4.344$ & $<0.001$ & - & - & - \\
\hline $\mathrm{pN} 3$ & 8.873 & $5.480-14.366$ & $<0.001$ & - & - & - \\
\hline \multicolumn{7}{|l|}{ Histological grade } \\
\hline GI & I & & & $\mathrm{I}$ & & \\
\hline $\mathrm{G} 2$ & 1.222 & $0.884-1.688$ & 0.225 & 1.545 & $0.95 \mathrm{I}-2.508$ & 0.079 \\
\hline G3 & 1.417 & $1.009-1.990$ & 0.044 & 2.066 & $1.234-3.457$ & 0.006 \\
\hline \multicolumn{7}{|l|}{$A B O$ blood group } \\
\hline Non-AB & I & & & 1 & & \\
\hline$A B$ & 1.007 & $0.765-1.505$ & 0.972 & 2.576 & $1.349-4.919$ & 0.004 \\
\hline \multicolumn{7}{|l|}{ Smoking } \\
\hline Never & I & & & - & & \\
\hline Ever & 1.073 & $0.765-1.505$ & 0.685 & - & - & - \\
\hline \multicolumn{7}{|c|}{ Alcohol consumption } \\
\hline No & 1 & & & I & & \\
\hline Yes & 1.620 & I.264-2.076 & $<0.001$ & 1.681 & $1.15 \mathrm{I}-2.464$ & 0.007 \\
\hline
\end{tabular}

Abbreviations: $\mathrm{Cl}$, confidence interval; $\mathrm{G}$, grade; $\mathrm{HR}$, hazard ratio; $\mathrm{N}$, node; $\mathrm{p}$, primary; $\mathrm{T}$, tumor. 
The $A B O$ gene is located on chromosome $9 \mathrm{q} 34$ and encodes glycosyltransferases,${ }^{23}$ which catalyze the step-bystep transfer of nucleotide donor sugars to the $\mathrm{H}$ antigen to form the A and B antigens. ${ }^{24}$ Aberrant glycosylation represents a hallmark of cancer development and progression. ${ }^{25}$ Thus, we hypothesize that patients with blood type AB are more susceptible to disease failure because their blood group antigens promote tumor cell invasion and the immune responses of ESCC cells. Further studies of the impact of blood type on tumor behavior or response to therapy could elucidate novel aspects of tumor biology and help guide individualized therapy for ESCC.

There are some limitations of the present study. First, this study is a single-center retrospective study and is not representative of the general population. Second, in order to avoid potential biases, patients enrolled in the present study were locoregional ESCC cases and underwent esophagectomy as curative treatment. Therefore, this study excluded patients with metastatic disease and those with unresectable ESCC. Thirdly, the detailed mechanism connecting the prognosis of ESCC patients and the ABO blood types remains unknown in the present study. Further explorations of the detailed mechanism may lead to the development of completely new cancer treatments.

In conclusion, the results of the present study show that $\mathrm{ABO}$ blood group is a prognostic factor for survival in patients with ESCC after esophagectomy. Patients with blood type $\mathrm{AB}$ had a significantly worse OS than patients with non- $\mathrm{AB}$ types, and this was especially in patients with negative LN. Our results should be verified by additional studies. Additionally, more research is needed to elucidate the association between $\mathrm{ABO}$ blood group and the genetic and biological features of ESCC.

\section{Acknowledgments}

This work was supported by grants from the National Natural Science Foundation of China (No 81402527), the SciTech Office of Guangdong Province (No 2013B021800157), and the Youth Foundation of Fujian Provincial Health and Family Planning Commission (No 2014-2-63).

\section{Disclosure}

The authors report no conflicts of interest in this work.

\section{References}

1. Siegel R, Ma J, Zou Z, Jemal A. Cancer statistics, 2014. CA Cancer J Clin. 2014;64(1):9-29.

2. Chen W, Zheng R, Zhang S, et al. The incidences and mortalities of major cancers in China, 2009. Chin J Cancer. 2013;32(3):106-112.
3. Rice TW, Blackstone EH, Rusch VW. 7th edition of the AJCC cancer staging manual: esophagus and esophagogastric junction. Ann Surg Oncol. 2010;17(7):1721-1724.

4. Rahbari NN, Bork $U$, Hinz $U$, et al. AB0 blood group and prognosis in patients with pancreatic cancer. BMC Cancer. 2012;12:319.

5. Cao X, Wen ZS, Sun YJ, Li Y, Zhang L, Han YJ. Prognostic value of $\mathrm{ABO}$ blood group in patients with surgically resected colon cancer. Br J Cancer. 2014;111(1):174-180.

6. Ouyang PY, Su Z, Mao YP, Liu Q, Xie FY. Prognostic value of ABO blood group in southern Chinese patients with established nasopharyngeal carcinoma. Br J Cancer. 2013;109(9):2462-2466.

7. Cihan YB. Significance of ABO-Rh blood groups in response and prognosis in breast cancer patients treated with radiotherapy and chemotherapy. Asian Pac J Cancer Prev. 2014;15(9):4055-4060.

8. Su M, Lu SM, Tian DP, et al. Relationship between ABO blood groups and carcinoma of esophagus and cardia in Chaoshan inhabitants of China. World J Gastroenterol. 2001;7(5):657-661.

9. Gong Y, Yang YS, Zhang XM, et al. ABO blood type, diabetes and risk of gastrointestinal cancer in northern China. World J Gastroenterol. 2012;18(6):563-569.

10. Kumar N, Kapoor A, Kalwar A, et al. Allele frequency of ABO blood group antigen and the risk of esophageal cancer. Biomed Res Int. 2014; 2014:286810.

11. Sun $\mathrm{P}, \mathrm{Chen} \mathrm{C}$, Zhang F, et al. The ABO blood group predicts survival in esophageal squamous cell carcinoma in patients who ever smoked: a retrospective study from China. Tumour Biol. 2014;35(7):7201-7208.

12. Yang $\mathrm{X}$, Huang $\mathrm{Y}$, Feng JF. Is there an association between $\mathrm{ABO}$ blood group and overall survival in patients with esophageal squamous cell carcinoma? Int J Clin Exp Med. 2014;7(8):2214-2218.

13. Nozoe T, Ezaki T, Baba H, Kakeji Y, Maehara Y. Correlation of ABO blood group with clinicopathologic characteristics of patients with esophageal squamous cell carcinoma. Dis Esophagus. 2004;17(2): 146-149.

14. Gates MA, Wolpin BM, Cramer DW, Hankinson SE, Tworoger SS. $\mathrm{ABO}$ blood group and incidence of epithelial ovarian cancer. Int J Cancer. 2011;128(2):482-486.

15. Wolpin BM, Chan AT, Hartge P, et al. ABO blood group and the risk of pancreatic cancer. J Natl Cancer Inst. 2009;101(6):424-431.

16. Ben Q, Wang K, Yuan Y, Li Z. Pancreatic cancer incidence and outcome in relation to $\mathrm{ABO}$ blood groups among Han Chinese patients: a case-control study. Int J Cancer. 2011;128(5):1179-1186.

17. Pandey M, Gautam A, Shukla VK. ABO and Rh blood groups in patients with cholelithiasis and carcinoma of the gall bladder. BMJ. 1995;310: 1639.

18. Tachibana M, Kinugasa S, Dhar DK, et al. Prognostic factors in nodenegative squamous cell carcinoma of the thoracic esophagus. Int J Surg Investig. 2000;1(5):389-395.

19. Lin $\mathrm{Y}, \mathrm{Su} \mathrm{X}, \mathrm{Su} \mathrm{H}$, et al. Prediagnostic smoking and postoperative survival in lymph node-negative esophagus squamous cell carcinoma patients. Cancer Sci. 2012;103(11):1985-1988.

20. Song Z, Wang J, Lin B, Zhang Y. Analysis of the tumor length and other prognosis factors in pT1-2 node-negative esophageal squamous cell carcinoma in a Chinese population. World J Surg Oncol. 2012; 10:273.

21. Melzer D, Perry JR, Hernandez D, et al. A genome-wide association study identifies protein quantitative trait loci (pQTLs). PLoS Genet. 2008;4(5):e1000072.

22. Gao S, Worm J, Guldberg P, et al. Genetic and epigenetic alterations of the blood group $\mathrm{ABO}$ gene in oral squamous cell carcinoma. $\mathrm{Br}$ J Cancer. 1996;73(4):420-423.

23. Devlin J, Elder PA, Gabra H, Steel CM, Knowles MA. High frequency of chromosome 9 deletion in ovarian cancer: evidence for three tumoursuppressor loci. Int J Cancer. 2004;109(2):230-237.

24. Yazer MH. What a difference 2 nucleotides make: a short review of ABO genetics. Transfus Med Rev. 2005;19(3):200-209.

25. Hakomori S. Glycosylation defining cancer malignancy: new wine in an old bottle. Proc Natl Acad Sci U S A. 2002;99(16):10231-10233. 


\section{Publish your work in this journal}

OncoTargets and Therapy is an international, peer-reviewed, open access journal focusing on the pathological basis of all cancers, potential targets for therapy and treatment protocols employed to improve the management of cancer patients. The journal also focuses on the impact of management programs and new therapeutic agents and protocols on
Dovepress

patient perspectives such as quality of life, adherence and satisfaction. The manuscript management system is completely online and includes a very quick and fair peer-review system, which is all easy to use. Visit http://www.dovepress.com/testimonials.php to read real quotes from published authors.

Submit your manuscript here: http://www.dovepress.com/oncotargets-and-therapy-journal 